\title{
HUBUNGAN WAKTU PEMBERIAN MAKANAN TAMBAHAN TERHADAP STATUS GIZI BAYI DI DESA JEMBUNGAN
}

\author{
Titik Anggraeni*, Tut Wuri Prihatin** \\ *Akademi Keperawatan Mamba'ul 'Ulum Surakarta \\ **STIKes Karya Husada Semarang \\ titikanggraeni_akpermus@yahoo.com
}

\begin{abstract}
Abstrak
ASI dapat mencukupi seluruh kebutuhan bayi akan zat gizi sampai berusia 6 bulan, sesudah itu bayi memerlukan makanan tambahan. Pemberian makanan pendamping ASI harus setelah 6 bulan, karena jika diberikan terlalu dini akan menurunkan konsumsi ASI dan bayi bisa mengalami gangguan pencernaan atau diare. Tujuan Penelitian ini adalah Menganalisis Hubungan waktu pemberian makanan tambahan dengan status gizi bayi.Jenis penelitian adalah Explanatory research dengan pendekatan cross-sectional. Jumlah populasi adalah 70 dan 42 sampel. Pengambilan sampel dengan metode random sampling, Metode pengumpulan data dengan kuesioner. Analisis data yang digunakan Kendall Tau $(\tau)$ dengan program SPSS.

Hasil Penelitian ini adalah (1) Waktu pemberian makanan tambahan sebagian besar ibu bayi memberikan pada usia kurang dari 6 bulan sebanyak $(81,0 \%)$. (2) Status gizi bayi hasil penimbangan adalah baik sebanyak (97,6\%). (3) Hasil Uji Kendall Tau $(\tau)$ tidak ada hubungan waktu pemberian makanan tambahan terhadap status gizi bayi sebesar 0,076 dengan nilai signifikansi 0,628. Simpulan : tidak ada hubungan waktu pemberian makanan tambahan terhadap status gizi bayi.
\end{abstract}

Kata kunci $\quad$ : makanan tambahan; waktu pemberian; status gizi bayi

\section{THE RELATION OF TIME OF ADDITIONAL FEEDING ON THE NUTRITIONAL STATUS OF INFANTS IN JEMBUNGAN VILLAGE}

\begin{abstract}
Breastfeeding can provide all the babies need for nutrients until they reach 6 months of age. After the babies need feeding. Additional feeding should be given after 6 months because if it is given too early will reduce the consumption of breastfeeding and the infant may experience indigestion or diarrhea. The purposes of this reseacrh was to analyze relationship of time of additional feeding on the nutritional status of infants. This is an explanatory research with cross-sectional approach. Of 70 populations, 42 were drawn as samples with random sampling method. Data collected with questioners. Data was anallized with Kendall Tau $(\tau)$. The results of this research are (1) Most mothers give additional feeding when their babies were less than 6 months of age $(81,0 \%)$. (2) The nutrients status of infants were good (97,6\%). (3) The result of Kendall Tau $(\tau)$ Test shows there were no relationship between time of additional feeding on the nutrients status of infants with the value of 0,076 and level of significant of 0,628 . There is no relationship of time of additional feeding on infant's nutritional status.
\end{abstract}

Key Words: additional feeding; the giving times of; infant's nutritional status 


\section{Pendahuluan}

Pertumbuhan adalah perubahan dalam arti pertambahan ukuran tubuh dan bagian-bagian lainnya sebagai akibat pertambahan jumlah sel-sel yang sama dengan sel-sel yang tumbuh tersebut. Dalam keadaan normal pertumbuhan anak-anak pada umur itu mengikuti pola tertentu sehingga pada umur tertentu didapatkan sosok tubuh anak dengan ukuran dan bentuk tertentu.

Makanan merupakan salah satu faktor yang mempengaruhi pertumbuhan dan perkembangan seorang anak setelah lahir, dimana makanan merupakan kebutuhan utama seorang anak untuk kelangsungan tumbuh yang optimal serta untuk keperluan kesehatannya (Samsudin, 2003).

Sampai usia 4-6 bulan, Air Susu Ibu (ASI) merupakan makanan terbaik untuk memenuhi kebutuhan fisiologis bayi (Soedibyo, 2002).

Diatas usia 6 bulan, kebutuhan gizi meningkat dan bayi memerlukan makanan yang lebih padat dan berserat. Oleh karena itu pemberian ASI perlu dilengkapi dengan pemberian berbagai jenis makanan bayi lain (makanan pendamping bayi atau makanan tambahan) yang cair mapun yang lebih padat. Dengan demikian peranan ASI dalam memenuhi kebutuhan gizi antara lain energi secara berangsur-angsur berkurang (Soedibyo, 2002).

Pada usia 5-6 bulan pencernaan bayi mulai kuat. Pemberian makanan pemdamping ASI harus setelah 6 bulan, karena jika diberikan terlalu dini akan menurunkan konsumsi ASI dan bayi bisa mengalami gangguan pencernaan atau diare. Sebaliknya bila makanan pendamping diberikan terlambat akan mengakibatkan anak kurang gizi bila terjadi dalam waktu panjang (Toeti Sunardi, 2000).

Keterangan tersebut menunjukkan bahwa masih adanya masalah dengan pemberian makanan tambahan dengan status gizi bayi sehingga peneliti tertarik melakukan penelitian tentang hubungan waktu pemberian makanan tambahan dengan status gizi bayi di Desa Jembungan.

Tujuan yang ingin dicapai dalam penelitian ini adalah untuk mengetahui dan menganalisa hubungan waktu pemberian makanan tambahan dengan status gizi di desa Jembungan. Adapun manfaat dari penelitian ini adalah menjadi acuan bagi masyarakat dalam menentukan waktu yang tepat dalam memberikan makanan tambahan bagi bayi. 


\section{Tinjauan Teoritis}

Makanan tambahan adalah makanan pengganti ASI yang mengandung sejumlah gizi yang di perlukan sebagai makanan tambahan bayi karena kebutuhan gizi bayi yang meningkat dan tidak seluruhnya dapat dipenuhi oleh ASI (Japan International Cooperation Agency dan Kanwil Depkes Jateng, 2002).

Fungsi makanan tambahan ialah untuk memenuhi kebutuhan bayi terhadap zat-zat gizi untuk keperluan pertumbuhan dan perkembangan bayi. Pada umur 6 bulan, bayi diperkenalkan dengan makanan tambahan, sehingga pada umur 6 bulan keatas bayi sudah terbiasa dengan makanan tersebut. (Morley, 1999). Penundaan pemberian makanan padat menghambat pertumbuhan jika energi dan zat-zat gizi yang dihasilkan oleh ASI tidak mencukupi lagi kebutuhannya (Pudjiadi Solihon, 2001).

Tabel 1. Anjuran Pemberian Makanan Tambahan

\begin{tabular}{ll}
\hline \multicolumn{1}{c}{ Umur anak } & \multicolumn{1}{c}{ PMT } \\
\hline $0-6$ bulan & ASI saja \\
$6-9$ bulan & Makanan lembut/bubur susu \\
$9-12$ bulan & Makanan semi keras/padat \\
$12-18$ bulan & Makanan dewasa dan \\
$18-24$ bulan & Disiplin \\
\hline
\end{tabular}

Sumber : Buku Pedoman Penggunaan Pengganti ASI, Depkes RI, (2008)

Gizi adalah suatu zat yang terdapat di dalam makanan yang dibutuhkan oleh tubuh untuk pertumbuhan. (Depkes, 2008). Status gizi adalah keadaan tubuh sebagai akibat konsumsi makanan dan penggunaan zat-zat gizi. Dibedakan antara status gizi kurang, baik, dan lebih. (Depkes, 2008).

Status gizi diartikan sebagai keadaan kesehatan fisik seseorang atau kelompok orang yang ditentukan dengan salah satu atau kombinasi dari ukuran-ukuran gizi tertentu. (Soekirman, 1999).

Penilaian status gizi pada penelitian ini menggunakan indeks berat badan menurut umur. Kemudian hasil pengukuran antropometrik tersebut dibandingkan dengan baku NHCS. Baku NHCS adalah tabel dan kartu yang berisi kombinasi 2 patokan populasi, yang keduanya merupakan kelompok besar dan dipilih secara random dari berbagai kelompok sosial ekonomi dan etnik di Amerika Serikat. WHO dan kelompok lainnya menggunakan NHCS sebagai patokan baku, karena introprestasi perbandingan yang dibuat terhadap NHCS adalah lebih berguna dan jenis bagi individu atau kelompok, sebab dibandingkan dengan data dari anakanak umur dan jenis kelamin tanpa memilih latar belakang sosial ekonomi dan suku 
bangsanya. Bayi adalah anak yang usianya kurang dari satu tahun (Hinchliff, 1999). Bayi ialah anak usia 0 sampai 12 bulan (Depkes, 2008).

\section{Metode Penelitian}

Jenis penelitian yang dilakukan adalah eksplanatory research dengan pendekatan cross sectional yaitu data yang menunjukkan titik waktu tertentu atau pengumpulannya dilakukan dalam waktu bersamaan (Handoko Riwidikdo, 2007). Penelitian dilaksanakan di Desa Jembungan, mulai bulan Januari sampai Mei 2014. Populasi dalam penelitian ini adalah semua bayi yang dibawa ibunya berkunjung pada KIA di Desa Jembungan sebanyak 70 bayi.

Sampel dalam penelitian berjumlah 42 bayi. Variabel bebas dalam penelitian ini adalah waktu pemberian makanan tambahan dan variabel terikat adalah status gizi bayi. Instrumen yang digunakan dalam penelitian ini adalah kuesioner, meliputi kuesioner identitas bayi dan ibu, waktu pemberian makanan tambahan dan status gizi bayi(berat badan pada penimbangan). Instrumen dalam penelitian ini merupakan tabel baku, jadi tidak perlu dilakukan uji validitas dan reliabilitas. Metode analisis data yang digunakan dalam penelitian ini adalah menggunakan korelasi Kendall Tau $(\tau)$. Korelasi Kendall Tau digunakan untuk mencari hubungan dan menguji hipotesis antara dua variabel atau lebih, bila datanya berbentuk ordinal atau ranking (Sugiyono, 2007).

\section{Hasil Penelitian}

Tabel 2. Distribusi responden berdasarkan kelompok waktu pemberian makanan tambahan di Desa Jembungan, Banyudono Tahun 2014.

\begin{tabular}{clcc}
\hline No & Umur Saat Pemberian Makanan Tambahan Pertama Kali & Jumlah & Persen \\
\hline 1 & PMT kurang dari 6 bulan & 34 & 81,0 \\
2 & PMT lebih atau sama dengan 6 bulan & 8 & 19,0 \\
\hline \multicolumn{2}{c}{ Jumlah } & 42 & 100 \\
\hline
\end{tabular}

Sumber : Data Primer 2014

Tabel 2 menunjukan bahwa kelompok waktu pemberian makanan tambahan pertama kali lebih banyak pada kelompok bayi umur kurang dari 6 bulan yaitu 34 bayi (81,0\%), pada kelompok bayi umur lebih atau sama dengan 6 bulan sebanyak 8 bayi (19,0\%). 
Tabel 3. Distribusi responden berdasarkan status gizi bayi di Desa Jembungan, Banyudono Tahun 2014

\begin{tabular}{|c|c|c|c|}
\hline No & Status Gizi Bayi & Jumlah & Persen \\
\hline 1 & Baik & 41 & 97,6 \\
\hline 2 & Kurang & 1 & 2,4 \\
\hline 3 & Buruk & 0 & 0 \\
\hline & Jumlah & 42 & 100 \\
\hline
\end{tabular}

Sumber : Data Primer 2014

Tabel 3 menunjukan bayi dengan status gizi baik yaitu sebanyak 41 responden (97,6\%), dan bayi dengan status kurang sebanyak 1 responden $(2,4 \%)$, serta tidak ada bayi dengan status gizi buruk.

Tabel 4. Hasil analisis statistik hubungan waktu pemberian makanan tambahan dengan status gizi bayi di Desa Jembungan.

\begin{tabular}{|c|c|c|c|c|}
\hline & & & $\begin{array}{c}\text { Pemberian Makanan } \\
\text { Tambahan }\end{array}$ & $\begin{array}{c}\text { Status Gizi } \\
\text { Bayi }\end{array}$ \\
\hline \multirow{8}{*}{$\begin{array}{l}\text { Kendall' } \\
\text { s tau_b }\end{array}$} & Pemberian & Correlation & 1.000 & .076 \\
\hline & Makanan & Coefficient & & \\
\hline & Tambahan & Sig. (2-tailed) & & .628 \\
\hline & & $\mathrm{N}$ & 42 & 42 \\
\hline & Status Gizi Bayi & Correlation & .076 & \\
\hline & & Coefficient & & \\
\hline & & Sig. (2-tailed) & .628 & 1.000 \\
\hline & & $\mathrm{N}$ & 42 & 42 \\
\hline
\end{tabular}

Hasil penelitian di dapatkan dari Uji Kendall Tau Corelations Coefficient sebesar 0,076 dengan nilai signifikansi 0,628. Hal ini dapat diartikan bahwa Ho di terima, jadi dapat dinyatakan tidak ada hubungan waktu pemberian makanan tambahan dengan status gizi bayi di Desa Jembungan.

\section{Pembahasan}

Dari pengujian dengan Kendall Tau $(\tau)$ diperoleh nilai sebesar 7,6\% dengan tingkat signifikansi lemah $(\tau=0,076 ; \mathrm{P}=0,628)$. Hal ini menunjukkan bahwa tidak ada hubungan waktu pemberian makanan tambahan dengan status gizi bayi di Desa Jembungan. Kemungkinan ada faktor-faktor lain yang berhubungan dengan status gizi bayi, antara lain :

\section{Pengetahuan Gizi}

Pengetahuan gizi ini sangat diperlukan untuk ibu terutama ibu yang mempunyai anak balita atau untuk pengasuh anak balita. Karena kebutuhan dan kecukupan gizi anak balita tergantung dari konsumsi makanan yang diberikan oleh ibu atau pengasuh anak. Tingkat pengetahuan gizi ibu sebagai pengelola rumah tangga akan berpengaruh pada macam bahan makanan yang 
dikonsumsinya. Misalnya ketidaktahuan akan hubungan makanan dan kesehatan. Dalam kehidupan sehari-hari sering terlihat keluarga yang sungguhpun berpenghasilan cukup akan tetapi makanan yang dihidangkan seadanya saja. Dengan demikian, kejadian gangguan gizi tidak hanya ditemukan pada keluarga yang berpenghasilan kurang akan tetapi juga pada keluarga yang berpenghasilan relatif baik (cukup). Keadaan ini menunjukkan bahwa ketidaktahuan akan faedah makanan bagi kesehatan tubuh merupakan sebab buruknya mutu gizi makanan keluarga, khususnya makanan anak balita (Sjahmien Moehji, 2002).

\section{Konsumsi ASI}

ASI diketahui mengandung zat gizi yang paling sesuai kualitas dan kuantitasnya untuk pertumbuhan dan perkembangan bayi. Jumlah dan komposisi ASI berbeda-beda dari hari ke hari sangat sesuai dengan kebutuhan artinya zat gizi yang masuk ke dalam tubuh akan sesuai dengan laju pertumbuhannya (Irianton Aritonang, 2003). Menurut Irianton Aritonang (2003), keunggulan ASI sudah tidak perlu diragukan lagi. ASI mengandung semua zat gizi yang diperlukan bayi, mengandung zat kekebalan terhadap penyakit, dan tidak perlu dibeli, sekaligus merupakan ungkapan rasa kasih sayang ibu kepada anak.

\section{Pendapatan Keluarga}

Pada umumnya jika tingkat pendapatan naik jumlah dan jenis makanan cenderung untuk membaik juga tetapi mutu makanan tidak selalu membaik (Suhardjo dkk, 1996). Anak-anak yang tumbuh dalam suatu keluarga miskin adalah paling rentan terhadap kurang gizi di antara seluruh anggota keluarga dan anak paling kecil biasanya paling terpengaruh oleh kekurangan pangan. Jumlah keluarga juga mempengaruhi keadaan gizi.

\section{Jarak Kelahiran}

Jarak kelahiran akan mempengaruhi status gizi anak dalam keluarga. Dengan adanya jarak kelahiran yang dekat maka kebutuhan makanan yang seharusnya hanya diberikan pada satu anak akan terbagi dengan anak yang lain yang sama-sama memerlukan gizi yang optimal.

Jika dalam masa dua tahun itu ibu sudah sudah hamil lagi, maka bukan saja perhatian ibu terhadap anak menjadi berkurang, akan tetapi ASI yang masih sangat dibutuhkan anak akan berhenti keluar. Anak yang belum dipersiapkan secara baik untuk menerima makanan pengganti ASI, yang kadang-kadang mutu gizi anak makanan tersebut juga rendah. Hal ini akan menyebabkan terjadinya gizi buruk (Sjahmien Moehji, 2002).

\section{Praktik Pemberian Makanan}


Menurut Dina Agoes Sulistijani dan Maria Poppy Herlianty (2003) semakin bertambah usia anak makin bertambah pula kebutuhan makannya, secara kuantitas maupun kualitas. Untuk memenuhi kebutuhannya tidak cukup dengan susu saja. Saat berusia 1-2 tahun perlu diperkenalkan pola makanan dewasa secara bertahap. Disamping itu anak pada usia 1-2 tahun sudah menjadi masa penyapihan. Anak disebut konsumen pasif karena sangat tergantung pada pengaturan ibunya. Pengaturan makanan anak usia dibawah lima tahun mencakup aspek pokok yaitu :1) Pemanfaatan ASI secara tepat dan benar. 2) Pemberian makanan pendamping ASI dan makanan sapihan serta makanan setelah usia setahun (Sjahmien Moehji, 2003).

Penyakit Infeksi.

Masa bayi dan balita sangat rentan terhadap berbagai penyakit. Infeksi bisa berhubungan dengan gangguan gizi melalui beberapa cara, yaitu mempengaruhi nafsu makan, dapat juga menyebabkan kehilangan bahan makanan, sehingga kebutuhan zat gizinya tidak terpenuhi. Secara umum defisiensi gizi sering merupakan awal dari gangguan defisiensi sistem kekebalan. Kaitan penyakit infeksi dengan keadaan gizi kurang merupakan hubungan timbal balik dan sebab akibat. Penyakit infeksi dapat memperburuk keadaan gizi, dan keadaan gizi yang jelek dapat mempermudah seseorang terkena penyakit infeksi ( I Dewa Nyoman Supariasa, 2002 ). Penyakit infeksi yang sering diderita : Diare dan ISPA.

\section{Pelayanan Kesehatan}

Upaya pelayanan kesehatan dasar diarahkan kepada peningkatan kesehatan dan status gizi anak sehingga terhindar dari kematian dini dan mutu fisik yang rendah. Peran pelayanan kesehatan telah lama diadakan untuk memperbaiki status gizi. Dengan pelayanan kesehatan masyarakat yang optimal kebutuhan kesehatan masyarakat akan terpenuhi. Salah satu bentuk pelayanan kesehatan yaitu kegiatan posyandu yang dapat memantau pertumbuhan dan perkembangan anak balita dengan penimbangan berat badan (BB) secara rutin setiap bulan (Arianton Aritonang, 2003).

Hasil penelitian ini mendukung penelitian yang telah dilakukan oleh dr. Joni wahyudi (1993) bahwa status gizi dipengaruhi oleh tingkat pendapatan keluarga (80,3\%), pendidikan ibu balita yang masih rendah $(64,8 \%)$, beban keluarga yang berat (jumlah anak banyak) dapat merupakan faktor kendala yang mengakibatkan buruknya kondisi gizi balita. Sanitasi lingkungan yang masih buruk dan masih tingginya angka kesakitan penyakit menular pada desa yang miskin, jelas merupakan faktor-faktor yang juga perlu diperhatikan.

\section{Simpulan Dan Saran}


Dari penelitian yang dilakukan di Desa Jembungan, dapat disimpulkan bahwa tidak ada hubungan waktu pemberian makanan tambahan dengan status gizi bayi di Desa Jembungan dengan nilai Uji Kendall Tau $(\tau)$ sebesar 0,076.

Meskipun tidak ada hubungan antara waktu pemberian makanan tambahan dengan status gizi pada bayi, peneliti sarankan orang tua/wali hendaknya memberikan makanan tambahan kepada bayinya tepat pada waktunya yaitu setelah bayi umur 6 bulan dan selalu membawa bayinya ke Posyandu untuk penimbangan berat badannya. Hal ini dilakukan agar status gizi bayi terpantau sesuai dengan tahap tumbuh kembang anak. Bagi peneliti selanjutnya, diharapkan melakukan penelitian eksperimental tentang hubungan pemberian ASI eksklusif dengan peningkatan status gizi bayi atau faktor-faktor lain yang meningkatkan status gizi bayi.

\section{DAFTAR PUSTAKA}

Depkes RI, 2003, Petunjuk Teknis Pemantauan Status Gizi (PSG) Anak Balita, $\quad$ Direktora Bina Gzi Masyarakat, Jakarta. , 2005, Buku Pedoman Petugas Lapangan Dalam Upaya Perbaikan Gizi Keluarga, Cetakan V, Jakarta. , 2008, Buku Pedoman Penggunaan Pengganti Air Susu Ibu, Jakarta. , 2008, Buku Kesehatan Ibu dan Anak: Gerakan Pemantauan Tumbuh Kembang Anak, Jakarta.

Dina Agoes Sulistijani, dan Maria Poppy Herlianty. 2003. Menjaga Kesehatan Bayi \& Balita, Puspa Swara, Jakarta

Eko Budiarto, 2002, Biostatistika untuk Kedokteran dan Kesehaan Masyarakat, EGC, Jakarta.

Handoko Riwidikdo, 2008, Statistik Kesehatan, Media Cendekia Press, Yogyakarta.

Hinchliff, sue, 1999, Kamus Keperawatan, Edisi 17, Penerbit Buku Kedokteran EGC, Jakarta. I Dewa Nyoman Supariasa., dkk. 2002. Penilaian status Gizi, Buku Kedokteran,Jakarta. Irianton Aritonang. 2003. Pemantauan Pertumbuhan Balita, Kanisius, Yogyakarta. Japan International Cooperation Agency \& Kanwil Depkes Jateng, 2002, Makanan Sehat Balita dan Ibu Hamil, Kanwil Depkes Jateng.

Morley, D., 1999, Prioritas di Negara Sedang Berkembang, hal. 136-176, Yayasan Essentia Medica, Yogya.

Notoatmojo, S, 2005, Metodologi Penelitian Kesehatan, Rineka Cipta, Jakarta

Pudjadi Solihon, 2001, Ilmu Gizi Klinis pada Anak, FKUI, Jakarta.

Samsudin, 2001, Perkembangan Makanan Bayi Dan Penggunaannya Yang Rasional Dalam Upaya Peningkatan Kualitas Anak Indonesia, Dalam Pengukuhan Guru Besar Tetap Dalam Ilmu Kesehatan Anak Fakultas Kedokteran Universitas Indonesia, Jakarta. , 2003, Perkembangan tentang Jenis, Istilah dan Pemanfaatan Makanan Bayi selain ASI, dalam simposium Makanan Bayi KONIKA VII, Jakarta.

Sjahmien Moehji. 2002. Ilmu Gizi I Pengetahuan Dasar Ilmu Gizi, Papas SinarSinanti, Jakarta.

Soekirman, 1999, Ilmu Gizi dan Aplikasinya, Jakarta. 
Soedibyo, 2002, Pelbagai Jenis Makanan Padat Untuk Pelengkap Makanan Bayi, Diajukan Pada PTB-IKA, Jakarta.

Sugiyono, 2007, Statistik Untuk Penelitian, Alfabeta, Bandung.

Soetjiningsih, 2001, Dasar-Dasar Metodologi Penelitian Klinis, Binarupa aksara, Jakarta. Suhardjo., dkk. 1996. Pangan, Gizi dan Pertanian, Universitas Indonesia, Jakarta.

Toeti Soenardi, 2000, Makanan Pendamping ASI, http//www.medicaonline.com 